\title{
Methodological lessons from a cohort study of high risk women in Tanzania
}

\author{
O Hoffmann, B Zaba, B Wolff, E Sanga, L Maboko, D Mmbando, F von Sonnenburg, M Hoelscher
}

Sex Transm Infect 2004;80(Suppl II):ii69-ii73. doi: 10.1136/sti.2004.011908

See end of article for authors' affiliations

.....................

Correspondence to: Dr O Hoffmann, Centre for Population Studies, London School of Hygiene and Tropical Medicine, 50 Bedford Square, London WC1B 3DP, UK; Oliver. Hoffmann@lshtm.ac.uk

Accepted for publication 6 September 2004

\begin{abstract}
Objectives: To describe the development, characteristics, and follow up of a high risk cohort of women in Tanzania. Differences in social background and sexual behaviour of women working in traditional and modern alcohol selling workplaces are shown.

Methods: Data from questionnaires four months before the enrolment of the cohort, at enrolment, and at 32 months were compared. Key informant interviews, social mapping exercises, and focus group discussions were held before the start of the cohort.

Results: In the absence of organised prostitution, two different groups of women with high risk exposure were identified during the baseline survey: female workers in modern alcohol selling places such as bars, guesthouses, and restaurants (barmaids) and in traditional places (local brew sellers). Overall, the population had a mean age of 27.7 years with barmaids tending to be younger ( 24.3 years) than local brew sellers ( 34.2 years). The main duration of stay in the current workplace was 2.1 years (barmaids 0.9 years; local brew sellers 4.1 years). Barmaids were more likely to have paying casual sex partners than local brew sellers and used condoms more regularly. Local brew sellers tend to be more stable with only $10 \%$ lost to follow up after 32 months compared with $24.4 \%$ of the bar workers.

Conclusions: Preliminary work revealed major differences in characteristics and behaviour between women working in modern and traditional alcohol selling outlets. Thorough preparation of the study, close monitoring of the cohort, and provision of selected benefits resulted in high retention rates over a 32 month project in a highly mobile population.
\end{abstract}

W omen working in places that sell alcohol along the Trans-African Highway are considered to be one of the highest risk groups for infection with HIV and STI in Africa. ${ }^{12}$ A study in northern Tanzania revealed an HIV prevalence of $73 \%$ among female bar workers. ${ }^{3}$ Similar prevalences have also been found in other African countries such as Ethiopia (1998, 74\%), Ivory Coast $(1995,61 \%)$, and South Africa (1997, 50\%).4-6 A study of 104 female bar workers in Mbeya Region in Tanzania in 1999 found 56\% of them to be HIV positive (Hoelscher, unpublished data). This was considerably higher than the HIV prevalence of 15\% among antenatal care attendees (aged 15-24 years) in Mbeya Region in the same year. ${ }^{7}$

Follow up of cohorts tends to be difficult, even in low risk populations. In rural Uganda, follow up in two different general population cohorts was $67 \%$ and $77 \%$ respectively after one year. ${ }^{89}$ In a police officer cohort in Dar es Salaam, Tanzania, $73 \%$ had at least one follow up visit after four years. ${ }^{10}$ Much lower follow up rates in female high risk groups were reported in three African settings. In Somalia, retention of 155 prostitutes was $44 \%$ after six months. ${ }^{11}$ In South Africa only 88 out of 263 HIV positive women recruited for a microbicide study returned for at least one follow up visit $(33.5 \%)^{12}$ whereas in Mombasa, Kenya $57.6 \%$ were reached after three years amongst prostitutes recruited into an HIV vaccine preparedness study. ${ }^{13}$ One major concern of low follow up rates is that they tend to underestimate HIV incidence because mobile women tend to have a higher sexual risk behaviour than those who are stable and more likely to stay in a cohort. This effect has been described for a female sex workers cohort in Thailand ${ }^{14}$ and might help to explain falling HIV incidences in African sex workers cohorts as well. ${ }^{13}$ Cohort studies are important to characterise sexual risk behaviour, mobility, and HIV/STI incidences in selected population groups and are needed to examine correlates of HIV seroconversion over time. However they are extremely difficult to establish and maintain. Lowndes and colleagues have therefore tried to estimate the HIV incidence of female sex workers in Cotonou by combining data from three serial cross sectional surveys of HIV/STI prevalence and sexual behaviour and assumptions on the sizes of the core groups. ${ }^{16}$ The Nairobi female sex workers cohort started in 1985 has been employing an open cohort design and their reports about follow up data are reduced to person years of follow up; actual follow up data are not reported. ${ }^{17}$ A recent study from this group used a closed cohort strategy and 341 out of 466 women completed two years of follow up $(73.1 \%) .{ }^{18}$

In 2000 a cohort study looking into HIV-1 superinfection and its behavioural, immunological, and virological correlates was commissioned in Mbeya Region. The study design involved three-monthly follow up rounds of 600 female bar workers for three years. In the first phase of this research, baseline studies were undertaken to establish knowledge about the target population and to highlight potential problems. A baseline survey of eligible women was then conducted in the 14 largest high transmission areas in the whole region to provide a sampling frame for the study. Subsequently, 600 high risk women aged 18-35 years were enrolled into the cohort study in those same 14 areas within Mbeya Region. The benefits for the study participants included free treatment for sexually transmitted infections (STIs), continuous health education, HIV counselling, and a remuneration of 8000 Tsh (US\$8) every three months for the time spent in the study.

The cohort study comprises research in the fields of virology, immunology, clinical medicine, and social behaviour as well as communication about behaviour change, STI treatment, and HIV counselling. The high risk population was chosen mainly because the virological and immunological 
research questions required a high HIV prevalence and incidence. Clinical and behavioural research components were included to assist in describing and interpreting laboratory based findings. Subsequently, these components developed into research projects in their own right.

In the light of cited follow up rates of other African studies with women working in high risk areas for HIV/STI, the major focus of this article concerns strategies used to identify and retain this marginalised group of women over a period of three years. Findings from the baseline studies are reported, together with the ways in which they were used during the implementation of the research study. The paper also highlights background characteristics, sexual behaviour, and follow up of women working in places where they are at high risk of contracting HIV and STIs, distinguishing women working in modern places (bar, guesthouse, and restaurant attendants) and those working in traditional alcohol selling outlets (local brew sellers).

\section{METHODS}

The baseline studies employed a variety of techniques, such as key informant interviews, social mapping, structured questionnaires, and participant observation. Selected variables from the baseline interviews were compared with findings from the enrolment questionnaire to check for sampling biases during enrolment into the study.

\section{Key informant interviews and social mapping}

Key informant interviews were held with government authorities and health officials in 20 places which were defined as high transmission areas for HIV and STI by the Regional AIDS Control Project. Discussion topics included identification of public places for social activities and specific questions about meeting places for sexual partners. A social mapping exercise was performed and all bars, guesthouses, restaurants, and places where the local brew was sold (known locally as pombe shops) were located on a sketch map. These meetings were also used to inform the local government authorities about the planned study.

\section{Focus group discussions}

Focus group discussions were held with barmaids in six sites and with sellers of local brew in two sites to explore the nature of their work. Topics included organisation of work, problems at work, characteristics of barmaids/local brew sellers, and alternative, additional income generating activities.

\section{Participant observation sessions}

Participant observation sessions were carried out in 13 selected sites and included bars, guesthouses, restaurants, and local brew shops. Notes were made of the size of the premises, facilities provided, and number of customers present. In total, 232 workplaces were visited in both urban $(46 \%)$ and rural areas (54\%)-half of them during the day, half of them in the evening.

\section{Baseline surveys}

Subsequently, about four months after the initial visit, the bar workers at 14 high risk places, selected with priority given to larger settlements, were invited to meetings in which the study was explained to them, and this occasion was used to gather some baseline data. Owners and workers who did not attend the meetings were traced to their respective workplaces. In total, 770 barmaids, 91 guesthouse attendants, 123 restaurant attendants, and 535 sellers of local brew (all of them females) participated in a short structured interview focusing on basic personal information and mobility history. In addition, 304 managers of bars, guesthouses, and restaurants and 110 owners of local brew shops participated in a short interview about their respective workplaces and the availability of male and female condoms.

\section{Enrolment}

In the first instance, the study enrolled those women who were already working in the various alcohol selling outlets during the baseline survey, which took place about four months after the initial visit. Lists of names of women who had participated in the baseline survey were compiled in each village and during the enrolment meetings their names were called first. This enrolment strategy deliberately left out those bar workers who were either highly mobile or who had only "dipped" into bar work temporarily. At enrolment, partner characteristics as well as information on sexual behaviour were obtained via structured interviews, including frequencies of permanent and casual partners, consistency of condom use, and factors leading to high risk behaviour such as payment for sexual intercourse.

Results from the structured baseline interviews and the structured enrolment interviews were compared to assess whether the study group differed from the source population in terms of age, birthplace, workplace, and duration of stay in the last workplace.

\section{RESULTS}

\section{Characteristics of main workplaces}

The key informants were asked to list common socialising places for people: bars, restaurants, and local brew shops were always named initially. Local brew shops and bars were most frequently identified as places to find casual sexual partners. Guesthouses, which are often connected to bars, were mostly described as places for sexual encounters with casual partners who had been met in bars. Brothels or other places of organised prostitution were never mentioned, because sex work is illegal in Tanzania and is therefore organised informally.

In the social mapping exercise, a total of 262 bars (range 5-28 per location), 97 guesthouses (range 2-13), 61 restaurants (range 2-14), and 124 local brew shops (range 2-20) were located on maps of the 20 most populous high transmission areas (range 14-47). It was also pointed out that bars, guesthouses, and restaurants attracted similar clients-mainly people from the middle class or above and wealthy travellers. Local brew shops attracted a wide mix of less well off people. Bars, guesthouses, and restaurants are usually found at roadsides and in town centres, whereas local brew shops tend to be situated on the periphery in small mud houses. Some are clustered in one spot (including small rooms and big halls); others are separate rooms in private houses. Bars are usually open for the whole day and offer soft drinks, beer, and spirits. Local brew shops operate in most areas throughout the day. They sell home prepared brew made from maize, millet, sorghum, bamboo, and other food crops. Whereas local brew is sold for 100 TSh (US\$0.10) per $500 \mathrm{ml}$, beer is sold for $500 \mathrm{TSh}$ (US\$0.50) per $500 \mathrm{ml}$ in the region. Participant observation showed that bars are usually bigger than brew shops, and many of them also have guest rooms, unlike local brew shops where no guest rooms are found. Compared with local brew shops, the facilities in bars are more modern, with music systems and TV often available. In the 64 bars surveyed, there were many more male customers (mean 9.4) than female (mean 2.9) but, when the presence of female bar workers is taken into account (mean 6.7), the sex ratio of people on the premises was almost even (sex ratio 0.98 male:female). By contrast, the 41 local brew shops attracted a larger clientele, with an average of 15.9 male customers and 8.0 female customers, who were 
served by an average of 4.8 female staff, so that the sex ratio was 1.24 in favour of males.

Between April and August 2000, the managers of 414 out of 544 premises $(76 \%)$ completed short questionnaires. A total of 1315 workers, of whom 1060 were female $(81 \%)$, were identified by 304 managers of bars, guesthouses, and restaurants. The local brew shop owners (110) identified 724 workers including 636 females $(88 \%)$. The total expected number of female workers (2228) in all 544 places is based on the average number of female workers in each establishment as reported by the managers. Bars have a higher turnover compared with local brew shops, with a mean duration of operation of 5.7 years compared with 9.5 years for local brew shops, of which $90 \%$ had operated more than one year.

\section{Characterising the study population}

According to the key informant interviews and the focus group discussions with women from the target group, the easiest way to find a casual sex partner is in a local brew shop among women typically identified as brew and food sellers and women drinking local brew. The price for one sexual act can be as little as one tin of local brew, which is 100 TSh (US\$0.10). The location of the acts might be outside or in construction sites. It is common knowledge that barmaids look for male customers as the salary paid for their work in the bar is very low, ranging from 2000-15 000 TSh per month (US\$2-15). In some cases no salary is paid at all. The price for one sex act with a barmaid was mentioned as starting from 1000 TSh (\$1) upwards. According to the focus group discussions with barmaids, sexual encounters without a condom tend to be better paid. Anal sex is also practised and the pay is much higher than for vaginal sex. Barmaids complained that sometimes the customer did not pay after intercourse and that they could not rely on anyone else's help because the business was a private agreement. Only in very few places were bar managers found acting as a link between a barmaid and a customer. In the focus group discussions nothing else was mentioned that could have pointed to organised prostitution.

From April to August 2000, short interviews were conducted: $65 \%$ (983) of the respondents were bar, guesthouse, and restaurant attendants and the remaining 35\% (535) local brew sellers. The age distribution and the mean duration of stay in the workplace are shown in table 1 . The place of birth of $68 \%$ of the barmaids is within the Mbeya Region, 29\% were born in another region in Tanzania and 3\% come from another country. Local brew sellers are more likely to be locals: $82 \%$ were born in Mbeya Region, whereas 16\% were from outside the region and $2 \%$ from outside Tanzania.

Comparing only women less than 35 years of age in the cohort and the baseline survey, the mean age for the cohort is 24.4 years and that of the general female high risk population
24.9 years. This age limitation also changes the duration of work at the current workplace: in the baseline survey 69\% worked less than one year and $12 \%$ more than three years, whereas in the cohort $56 \%$ worked less than one year and $10 \%$ more than three years.

\section{Background characteristics and sexual behaviour of cohort participants}

The cohort was established between September and December 2000 and included 431 bar, guesthouse, and restaurant attendants (72\%) and 169 local brew (pombe) sellers $(28 \%)$. The particulars of age and duration of stay in the current work are shown in table 1 . The place of birth in the cohort was mainly in Mbeya Region (72\%), followed by another region within Tanzania (24\%) and $4 \%$ outside Tanzania.

At enrolment almost all participants reported having permanent partners (bar $88 \% v$ brew $90 \%$ ). Local brew sellers more often lived together with their permanent partners than bar workers $(66 \% v 22 \%)$, whose partners were also less likely to come from the local area $(64 \% v 88 \%)$. These factors might make it easier for bar workers to organise sexual encounters with casual partners $(50 \% \vee 25 \%$ for brew workers in the three months preceding enrolment) and bar workers' partners were also more likely to pay for sexual intercourse ( $47 \% \vee 22 \%$ of all casual partners). Casual partners of bar workers were about nine years older whereas those of local brew sellers were about seven years older on average. Bar workers were more likely to have casual partners (65\%) who were not living in the neighbourhood, compared with those of local brew sellers (49\%). Ever use of condoms with casual partners was reported by $80 \%$ of the bar workers compared with $56 \%$ of the local brew sellers. A similar relation was found in condom use with permanent partners. Fifty four per cent of bar workers and $24 \%$ of local brew sellers ever used a condom with their permanent partners.

\section{Follow up}

From March to June 2003, 32 months after the enrolment, the overall retention was $70 \%$. Genuine dropouts (either lost to follow up or missing at least two follow up rounds) accounted for $19 \%$, death of the initial participants $9 \%$, and $2 \%$ were temporarily absent. The main reason for death was AIDS related $(67 \%)$ followed by pregnancy/birth related (18\%) and unknown/other causes (15\%). The follow up rate dropped from $86 \%$ after one year to $76 \%$ in the second year (table 2). Local brew sellers were more likely to be retained in the cohort than barmaids, with the proportion remaining as a fraction of the baseline being $66 \%$ for the barmaids and $81 \%$ for the local brew sellers. The difference is mainly due to a higher number of dropouts among the barmaids, as the death rate is similar in these two groups. Figure 1 shows the trend

\begin{tabular}{|c|c|c|c|c|c|c|c|c|c|}
\hline \multirow[b]{2}{*}{ Characteristics } & \multicolumn{3}{|l|}{ Baseline } & \multicolumn{3}{|c|}{ Enrolment } & \multicolumn{3}{|c|}{32 month follow up } \\
\hline & All & Bar & Pombe & All & Bar & Pombe & All & Bar $\mathrm{P}$ & Pombe \\
\hline Number & 1528 & 983 & 535 & 600 & 431 & 169 & 421 & 284 & 137 \\
\hline Percentage & 100 & 65 & 35 & 100 & 72 & 28 & 100 & 67 & 33 \\
\hline \multicolumn{10}{|l|}{ Age } \\
\hline Mean (years) & 27.7 & 24.3 & 34.2 & 25.5 & 24.6 & 27.8 & 28.7 & 27.6 & 30.8 \\
\hline$<20(\%)$ & 16 & 23 & 3 & 9 & 10 & 4 & 1 & 1 & 0 \\
\hline$\geqslant 30(\%)$ & 27 & 8 & 60 & 19 & 12 & 38 & 34 & 25 & 53 \\
\hline \multicolumn{10}{|l|}{ Stay } \\
\hline Mean (years) & 2.1 & 0.9 & 4.1 & 2.2 & 1.7 & 3.4 & 5.0 & 4.4 & 6.2 \\
\hline$<1$ year $(\%)$ & 62 & 77 & 34 & 58 & 65 & 40 & 0 & 0 & 0 \\
\hline$\geqslant 3(\%)$ & 18 & 7 & 39 & 29 & 23 & 46 & 72 & 65 & 87 \\
\hline
\end{tabular}



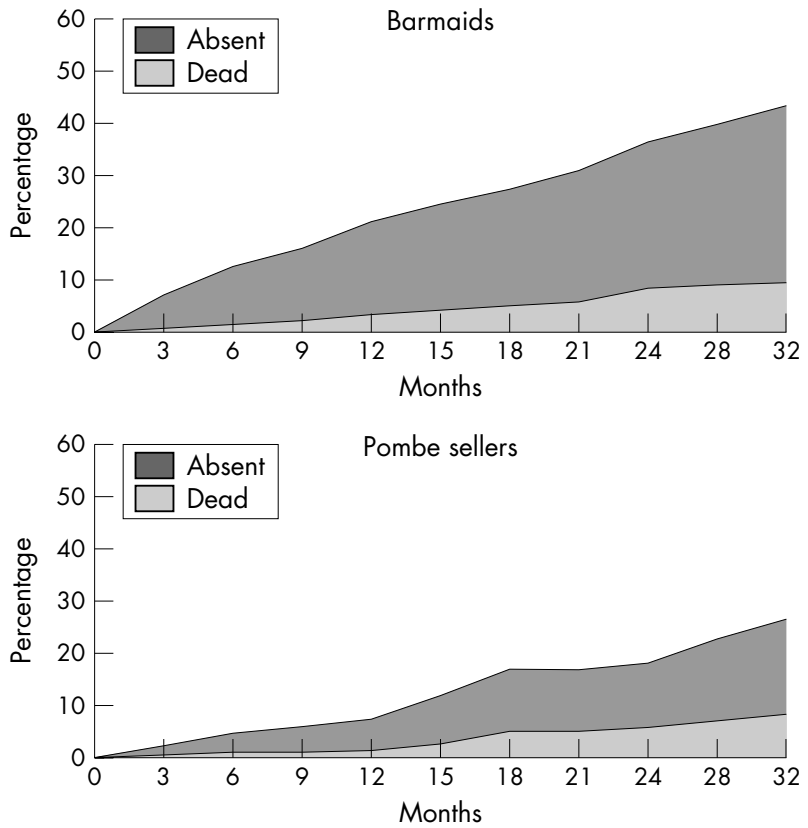

Figure 1 Trends in retention of participants in three-monthly follow ups, among barmaids and local brew (pombe) sellers in Mbeya region, Tanzania, by reasons for non-follow up.

over time according to different reasons among barmaids and local brew sellers.

\section{DISCUSSION}

Methodological lessons learned for retaining a mobile and marginalised study population

It was foreseen that the most difficult task concerning the planned cohort would be to take account of the mobility of the study participants. Overall only $12 \%$ of the eligible population worked more than three years in the same workplace but the study aimed to follow up each study participant over three years. The remarkable retention over 32 months can be attributed to the following factors:

- The baseline survey established inside knowledge of the target group, which was used to set up the cohort.

- Trust within the target group, their employers, and local authorities was built before the study participants were enrolled and this trust was maintained throughout the study. Crucial for the trust between the study participants and the study team was also the fact that the only person to know a participant's HIV result was her HIV counsellor but no other staff member in direct contact with the participant knew any HIV result.

- The same HIV counsellor always did pretest and post-test counselling including long term counselling and this continuity was appreciated by the women. One difference from similar cohorts might be that the same study team conducted all study related activities including mobilisation meetings before the enrolment, tracing activities, and health education.

- Initial seminars with all members of the study team ensured that the team always spoke with one voice and incipient rumours were immediately addressed.

This careful approach of the study team during enrolment and subsequent visits together with the benefits of free STI treatment and a remuneration for travel and time facilitated high follow up rates. It also kept the participants comfortable during study visits where virtually no refusals to any examination or interview questions were met.

\section{Identification of target group and differences between barmaids and local brew sellers}

The baseline study was conducted in order to define the target population for the study. From the start it became clear that formal prostitution is unknown in Mbeya Region. However, it seemed feasible to study women working in high risk establishments. Therefore, to meet the aim of a study population with a high prevalence and incidence of HIV, places of high social interaction were selected. These included bars, guesthouses, restaurants, and local brew shops.

The findings of the baseline studies showed clear differences between barmaids and local brew sellers. It became clear that local brew sellers are more stable and therefore probably also more integrated into the society than barmaids. The latter are younger and more mobile, as are guesthouse attendants and restaurant workers. The last three categories were grouped together for analysis. The age and mobility differences led the study team to form separate reporting groups wherever possible for clusters of local brew sellers on one hand, and barmaids, guesthouse attendants, and restaurant workers on the other, in order to ensure that participants felt comfortable with their peers. This clustering will be taken into account when analysing the cohort data.

Different patterns of sexual behaviour were reported. Local brew sellers are less likely to report casual partners and to use condoms, both with casual and permanent partners. Among other reasons this might be due to the limited access to condoms in their workplaces as reported by the managers. Non-use of condoms, however, is common in both groups, increasing the risk for transmission of HIV and STI in these premises. The age difference of bar workers and their casual partners is higher than that of local brew sellers. Bar workers also seem to be more likely to acquire new HIV strains because they have more partners coming from outside their community than do local brew sellers.

The age limit in the cohort led to over sampling of barmaids relative to local brew sellers. However, after 32 months of follow up the distribution between the two groups came closer to the baseline distribution because local brew sellers had a higher follow up rate. It is possible that the study in itself may have influenced the propensity of workers to stay in the same workplace or continue with the same type of work, and therefore the mean duration in work has increased in the cohort, especially in barmaids, compared with the general bar worker population (table 1). Ageing and

Table 2 Percentage of original study participants still present, dropped out, or dead at each three-month follow up

\begin{tabular}{lrrrrrrrrrr}
\hline Follow up (months) & \multicolumn{1}{c}{$\mathbf{3}$} & $\mathbf{6}$ & $\mathbf{9}$ & $\mathbf{1 2}$ & $\mathbf{1 5}$ & $\mathbf{1 8}$ & $\mathbf{2 1}$ & $\mathbf{2 4}$ & $\mathbf{2 8}$ & $\mathbf{3 2}$ \\
\hline Still present (\%) & 95 & 91 & 89 & 86 & 83 & 81 & 79 & 76 & 74 & 70 \\
Dropped out or absent (\%) & 5 & 7 & 9 & 11 & 13 & 14 & 15 & 16 & 18 & 21 \\
Dead (\%) & 1 & 2 & 2 & 3 & 4 & 5 & 6 & 8 & 9 & 9 \\
\hline
\end{tabular}


selection effects together caused the age distribution of barmaids at follow up to become less representative of their baseline age distribution than their enrolment age distribution. However for local brew sellers, the ageing effects counteracted the initial selection effects, so that their follow up age distribution is closer to the baseline age distribution than was their enrolment age distribution.

\section{CONCLUSION}

The necessity to identify a high risk population at first led to a careful approach involving many different data collection methods during the baseline survey. This exercise exposed the study team to the world of bar work in Mbeya Region and the lessons learned from this were a key factor in avoiding major problems during enrolment of the cohort. Thorough planning, close monitoring of the cohort, and provision of carefully selected benefits for the study participants were the major factors for good retention rates. The setting of this cohort provides a good source of sexual behaviour data and their changes over time, and different data collection methods (face-to-face interviews, self-administered formats and diaries) will be analysed to contribute to the overall aim of improved measurement of sexual behaviour in the era of HIV/AIDS.

\section{ACKNOWLEDGEMENTS}

We are grateful to the HIV-Superinfection Study-Barworkers Health Project (HISIS-BHP) team of the Mbeya Medical Research Program and the women who participated in the study. This work was conducted in the framework of the HISIS study group that includes the following members: D Birx, H Grosskurth, R Hayes, M Hoelscher, O Hoffmann, E Lyamuya, L Maboko, B Malaza, D Mmbando, F McCutchan, F Mhalu, M Pletschette, G Riedner, M Salminen, E Samky, F von Sonnenburg, J Todd, C Williamson, B Wolff, B Zaba.

\section{CONTRIBUTORS}

All authors commented on draft versions of the paper. $\mathrm{OH}$ designed the baseline study, developed the protocol, supervised the field work, analysed and interpreted the data, and was the lead writer; BZ codesigned the study, advised on the analysis and the interpretation of the results; BW, LM, DM, FS codesigned the study, advised on the implementation of the study and the interpretation of the results; ES assisted in the development of data collection instruments and was responsible for field work; $\mathrm{MH}$ designed the cohort study and assisted in the manuscript preparation.

\section{Authors' affiliations}

O Hoffmann, F von Sonnenburg, M Hoelscher, Department of Infectious Diseases and Tropical Medicine, University of Munich, Germany
O Hoffmann, B Zaba, B Wolff, Centre for Population Studies, London School of Hygiene and Tropical Medicine, UK

E Sanga, L Maboko, Mbeya Medical Research Programme, Tanzania D Mmbando, Mbeya Regional Medical Office, Mbeya, Tanzania

The study was supported by the European Commission, DG XII, INCODC FP5 and FP6, ERBICA4-10007; ERBICA4-20035

\section{REFERENCES}

1 Piot P, Laga M. Prostitutes: A high risk group for HIV infection? Soz Praeventivmedizin 1998;33:336-9.

2 Plummer FA, Nagelkerke NJ, Moses S, et al. The importance of core groups in the epidemiology and control of HIV-1 infection. AIDS 1991;5(Suppl 1):S169-76.

3 Nkya WM, Gillespie SH, Howlett W, et al. Sexually transmitted diseases in prostitutes in Moshi and Arusha, Northern Tanzania. Int J STD AIDS 1991;2:432-5.

4 Aklilu M, Messele T, Tsegaye A, et al. Factors associated with HIV-1 infection among sex workers of Addis Ababa, Ethiopia. AIDS 2001;15:87-96.

5 Ghys PD, Diallo MO, Ettiegne-Traore V, et al. Genital ulcers associated with human immunodeficiency virus-related immunosuppression in female sex workers in Abidjan, Ivory Coast. J Infect Dis 1995;172:1371-4.

6 Ramjee G, Karim SS, Sturm AW. Sexually transmitted infections among sex workers in KwaZulu-Natal, South Africa. Sex Transm Dis 1998;25:346-9.

7 Jordan-Harder B, Koshuma YA, Pervilhac C, et al. Hope for Tanzania: lessons learned from a decade of comprehensive AIDS Control in Mbeya Region. Tanzania, GTZ and Ministry of Health, 2000.

8 Mulder D, Nunn A, Kamali A, et al. Decreasing HIV-1 seroprevalence in young adults in a rural Ugandan cohort. BMJ 1995;311:833-6.

9 Wawer MJ, Sewankambo NK, Berkley S, et al. Incidence of HIV-1 infection in a rural region of Uganda. BMJ 1994;308:171-3.

10 Bakari M, Lyamuya E, Mugusi F, et al. The prevalence and incidence of HIV-1 infection and syphilis in a cohort of police officers in Dar es Salaam, Tanzania: a potential population for HIV vaccine trials. AIDS 2000;14:313-20.

11 Ahmed HJ, Omar K, Adan SY, et al. Syphilis and human immunodeficiency virus seroconversion during a 6-month follow-up of female prostitutes in Mogadishu, Somalia. Int J STD AIDS 1991;2:119-23.

12 Connolly CA, Ramjee G, Sturm AW, et al. Incidence of Sexually Transmitted Infections among HIV-positive sex workers in KwaZulu-Natal, South Africa. Sex Transm Dis 2002;29:721-4.

13 Baeten JM, Richardson BA, Martin HL Jr, et al. Trends in HIV-1 incidence in a cohort of prostitutes in Kenya: implications for HIV-1 vaccine efficacy trials. J Acquir Immune Defic Syndr 2000;24:458-64.

14 Beyrer C, Brookmeyer R, Natpratan C, et al. Measuring HIV-1 incidence in northern Thailand: prospective cohort results and estimates based on early diagnostic tests. J Acquir Immune Defic Syndr Hum Retrovirol 1996;12:495-9.

15 Fowke KR, Nagelkerke NJ, Kimani J, et al. Resistance to HIV-1 infection among persistently seronegative prostitutes in Nairobi, Kenya. Lancet 1996;348:1347-51

16 Lowndes $\mathrm{CM}$, Alary $\mathrm{M}$, Meda $\mathrm{H}$, et al. Role of core and bridging groups in the transmission dynamics of HIV and STIs in Cotonou, Benin, West Africa. Sex Transm Infect 2002;78(Suppl 1):i69-77.

17 Kaul R, Kimani J, Nagelkerke NJ, et al. Risk factors for genital ulcerations in Kenyan sex workers. The role of human immunodeficiency virus type 1 infection. Sex Transm Dis 1997;24:387-92.

18 Kaul R, Kimani J, Nagelkerke NJ, et al. Monthly antibiotic chemoprophylaxis and incidence of sexually transmitted infections and HIV-1 infection in Kenyan sex workers: a randomized controlled trial. JAMA 2004;291:2555-62. 